\title{
The influence of COVID-19 on grid parity of China's photovoltaic industry
}

\author{
Yazhi Song $\mathbb{B} \cdot$ Tiansen Liu $\cdot$ Yin Li $\cdot$ Bin Ye
}

Received: 30 May 2020/Accepted: 18 August 2020/Published online: 28 August 2020

(C) Springer Nature B.V. 2020

\begin{abstract}
With the more efficient involvement of both technology and policy factors in China's whole industry-chain, the year 2020 is a key period for photovoltaic (PV) industry to achieve grid parity. In this context, COVID-19 may trigger a certain timedelay in new installed PV projects, thereby bringing an uncertain influence on the whole PV industry. To forecast the influence degree and influence cycle of COVID-19 on PV industry, this paper firstly clarifies the key features of epidemic situation as well as the basic rule of such pandemics' transmission along industry-chain. Then this paper constructs a system dynamics model targeting at cost accounting of PV power generation under the influence of COVID-19 and thus forecasts the variation rules, superposition
\end{abstract}

\section{Y. Song $(\bowtie)$}

Business School, Jiangsu Normal University, Xuzhou, China

e-mail: songyazhi@jsnu.edu.cn

T. Liu

School of Economics and Management, Harbin

Engineering University, Harbin, China

Y. Li

Sun Yat-sen Business School, Sun Yat-sen University, Guangzhou, China

B. Ye $(\square)$

School of Environmental Science and Engineering,

Southern University of Science and Technology,

Shenzhen, China

e-mail: yeb@sustech.edu.cn effects and influence cycle of levelized cost of energy (LCOE) of PV power generation and the operations cost of each sub-system. Empirical results show that PV industry has a lag response to the COVID-19 for 1 quarter and periodic response for 4 quarters, which is mainly embodied in the rise of short-term production cost. At the same time, the influence of COVID-19 on the upstream firms of PV industry is stronger than that on downstream firms. With the gradual recovery of whole industry-chain, LCOE of PV power generation will rapidly return to the previous expected level of grid parity by the end of 2020 .

Keywords COVID-19 - Photovoltaic industry · LCOE cost $\cdot$ System dynamics analysis · China

\section{Introduction}

China's energy structure is experiencing a major reform (Ye et al. 2017, 2019). The aim and specific path to achieve this reform are the actual emission reduction as well as grid parity between traditional and clean energy (Chen et al. 2014; Mamat et al. 2020). Under the dual influences of policy regulation and fiscal subsidy, China's photovoltaic (PV) industry has achieved a great-leap forward development (Ding et al. 2016; Wang et al. 2019; Zhu et al. 2019). The year of 2020 is a critical period for China's PV power 
generation, in which the development of PV industry is moving from the fiscal subsidy dependence to grid parity (Yao and Cai 2019). Supported by fiscal subsidy, the desires of PV industry involving in power generation have significantly enhanced. Currently, the grid parity of PV power in China is mainly based on the "benchmark price of desulfurized coal." In other words, compared with the traditional coal-fired power, the grid parity of PV power has a considerable competitive edge. Since the benchmark price of desulfurized coal is still low, it always needs a further reduction in the levelized cost of energy (LCOE) of PV power generation. However, due to the outbreak of COVID-2019, a large number of PV power generation firms are experiencing a labor shortage, a rise of logistics time-cost and even the logistics stagnation, which triggers a difficulty in the transportation process of raw materials and semi-finished products. In addition, the subsequent outbreak and constant spread of COVID-2019 overseas may trigger a new export demand after the recovery of production in PV industry, which will increase the uncertainty of this industry. In this context, PV power bidding projects, which have not been completed in 2019, cannot be carried out in 2020. These actual dilemmas will trigger a shrinking trading volume along PV industry-chain at both supply and demand sides. Therefore, it can be concluded that in a high probability, the cost of PV power generation projects will increase because the contraction of supply side is more intense than that of demand side in China's PV markets in the short term. While in the mid-and long term, the lack of market demands will bring a fall of construction cost of PV power system, and it will also increase the investment risk of VP power generation projects (Cai et al. 2019). What's more, the influence of pandemics on each link of PV industry-chain is quite different, and with an increasing consumption of ingredients and inventory by PV modules firms before the Spring Festival 2020, some small- and medium-sized PV power generation firms experienced a production stagnation. In this case, the influence intensity and duration of COVID19 on PV industry need to be measured, and the future photoelectric revenue under the pandemic shock should be also forecasted, which provides an underpinning for firms' decision-making in fostering new economic growth points to respond to the challenge of COVID-19.
The pandemics always negatively influence economic situation, and its influence on PV industry has a certain time-delay effect. Based on the actual influence of SARS on China's economy in 2003, the pandemic influenced the capital-using industries for around 1 quarter (Li 2003). Restricted by the population flowing, COVID-19 will delay the recovery of production of PV industry for 2-3 weeks. However, for China's PV industry that has been incorporated into global PV industry-chain, due to the inconsistent time-point of recovery of production in each firm in relation to the supply chain and extension of logistics time, China's PV industry is more likely to experience a shortage of raw materials. It will trigger a fall of productivity in the whole industry-chain due to the untimely supply from upstream firms (Binz et al. 2017; Liu and Liu 2019). Judging from this, the influence of COVID-19 on PV industry will continue for a long time.

The essence of pandemics is a kind of emergency. Prior studies concluded that such emergency can influence PV industry from internal and external aspects (McBee et al. 2019; Mehrjerdi 2019). The internal emergency is mainly originated from the imbalance of power supply and demand caused by power failure and load variation, which needs a rapid check and then an adjustment of PV power grid (Schmitz et al. 2019; Al Hadi et al. 2020). External emergency is mainly caused by the change of environmental factors in PV industry that include policy involvement, market competitiveness, technology progress and financing channels (Sun et al. 2014; Liu et al. 2016; Mirzania et al. 2019; Moslehi and Reddy 2019). For example, the emergencies like financial crisis and imbalance of supply and demand may trigger a rise of market risks of PV industry and then influence the whole industry-chain (Ibarloza et al. 2018). The release of " 531 New Deal" slows down the PV industry in China that experienced a rapid development earlier, which results in a significant fall in new installed capacity (Corwin and Johnson 2019). Compared with the influence of single-factor change on the price of PV power, pandemics will trigger a change of policy adjustment, market environment, financing channel and some other response measures. Therefore, the joint effect of multiple factors will increase the difficulty in forecasting the influence of COVID-19 on China's PV industry. 
A key link of quantifying the influence intensity and cycle of COVID-19 on grid parity of PV power generation is to analyze the main features of China's PV industry-chain, which can also help clarify the general rule of pandemics on LCOE transmission along PV industry-chain. In this regard, it needs to develop a time-delay cost transmission model embedded in the PV industry-chain and thus characterize the actual influence of COVID-19 on the LCOE of PV power generation. Based on Ding et al. (2020), policy, technology, market and operations efficiency of PV firms are key factors that influence the layout structure of China's PV industry. Fang et al. (2020) argued that China's PV industry-chain is long, and the close collaboration among upstream and downstream firms is a key premise for promoting PV technology innovation and thus reduces electricity consumption cost. However, with respect to the upgrading path of PV industry-chain, Chen and Su (2018) found that the efficiency and cost reduction in PV power generation system by decomposing PV industry-chain and developing technology innovation in each production link are not as optimistic as that in whole industry-chain, which indicates that technology and cost input are not evenly distributed in each production link of China's PV industry. By further analyzing this case, it can be found that each link shows a "topology structure" rather than a "chain structure," thereby increasing the dissipation risk of the whole PV industry. Overall, China's PV industry-chain has features of products/ services homogeneity, fierce market competition, and technology heterogeneity, which makes PV industry in the period of meager profit (Wang and Wang 2018). By using the discrete state equation, Shang (2017) concluded that the variation of time-delay factors among industrial sectors depends on production cost and output value. In addition, $\mathrm{Li}$ et al. (2010) simulated the influence of single factor on production cost system by developing differential equation with considering the time-delay.

With respect to the specific time-delay model, it has been elaborated that the general rule of time-delay effect can be obtained by involving time-series terms into the "input-output" model (Tong 2010). Under the guidance of a view of system science that is "every system must have its own structure, and system structure determines the system function," prior studies believed that it needs to analyze internal influence mechanism and firms' feedback behavior targeting at the emergency from the perspective of system (Lane 1999). By the mathematical model, it can develop the causal relationship among the variations of different production forms (Ren et al. 2020). The system dynamics integrates both qualitative and quantitative methods, which can help intuitively show the transmission path among variables and the chainreaction intensity under the variation of internal variables. Accordingly, when analyzing the general rule of total subcontract trading cost, Sun et al. (2019) argued that system dynamics method can effectively match the dynamic cost influence of different factors, and the sensitivity test targeting at variables can help develop the corresponding response strategies. In addition, more studies argued that the system dynamics method can show a favorable result in both the midand long-term forecast and system's feedback under the influence of multi-factors (Zhu et al. 2018; Starnini et al. 2019; Ntemi and Kotropoulos 2020).

By analyzing the essence of pandemics' influence, this paper will use the system dynamics model to quantify the influence of COVID-19 on China's PV industry. Specifically, this paper contributes to following knowledge areas. First, we will provide theoretical underpinnings for China's government to improve fiscal subsidy policies by analyzing the actual influence of COVID-19 on PV industry and exploring both the specific influence path and time-delay effect on PV power investment. Second, we forecast the PV power investment cost under the influence of COVID19 and dual-pressures of domestic and overseas markets, which provides a decision-making basis for PV firms and PV power generation stations to grasp market prospects and reduce investment risks. Third, our cost accounting model for PV power generation can rapidly forecast such cost under the variation of system parameters, which provides a tool for the realtime quotation of PV power investment projects. This paper is helpful for the academic community to understand the impact mechanism and specific path of the pandemic shock on PV industry. The results of this paper also help the government to forecast the time of grid parity of PV under the impact of the COVID-19. At the same time, it provides a quantitative tool for PV firms to mitigate market risks and grasp investment opportunities.

The rest of this paper is structured as follows. "The framework of PV industry's cost system and subsystem design" section elaborates the manifestation of 
time cost in PV production cost and the transmission path along PV industry-chain. Then we develop the PV production cost system framework and clarify the specific indicators in each sub-system. Based on the system dynamics model, "The forecast model for cost of PV power generation based on system" section develops the model to quantify PV production cost under the time-delay condition with designing the research variables. "Results and analysis" section simulates the influence of COVID-19 on PV power generation cost. "Conclusions and research implications" section concludes this paper and accordingly proposes research implications.

\section{The framework of PV industry's cost system and sub-system design}

In general, PV industry-chain includes five production processes that are involved in upstream, midstream and downstream link of firms, as shown in Fig. 1.

From the perspective of international division of labor, China, which is the most important world factory and absolute manufacturing center in the global PV industry-chain, has more than $80 \%$ of PV industry production capacity. As novel coronavirus pneumonia has the features of global pandemic, the impact of COVID-19 on global PV industry has shifted from the beginning of upstream manufacturing side to the import and export trade as well as downstream firms. The influence of pandemics on PV industry mainly includes the time-delay of recovery of production, shortage of labor, fall in logistics efficiency, rise of production cost, tightening supply of raw materials, and uncertain prospects of export trading (Javaid et al. 2020; Vaka et al. 2020). At the manufacturing end of PV modules, the transportation time of raw materials will be extended, with the use rate of production capability of whole industry-chain decreasing and operations cost of whole industrychain increasing. At the application end of PV modules, it is likely that the proportion of abandoned electricity will gradually increase due to the failure of PV power generation projects in linking national grid schedules, which has a negative influence on the operations and maintenance of PV power generation. In the process of market financing, the time-point of manufacturer's funds recovery will be delayed, which brings a difficulty for small-scale and cash-flow intensive manufacturers in capital turnover. In terms of policy release in PV industry, COVID-19 triggers fiscal subsidies not to be carried out in time, and the postponement of bidding submission and verification sequencing is also influencing the start-up time of bidding projects. Accordingly, the influence of COVID-19 is mainly embodied as the time-delay of $\mathrm{PV}$ power generation projects. The chain reaction of demand and installed capacity by time-delay is embodied in the demand postponement that changes from the first quarter to the second or third quarter,

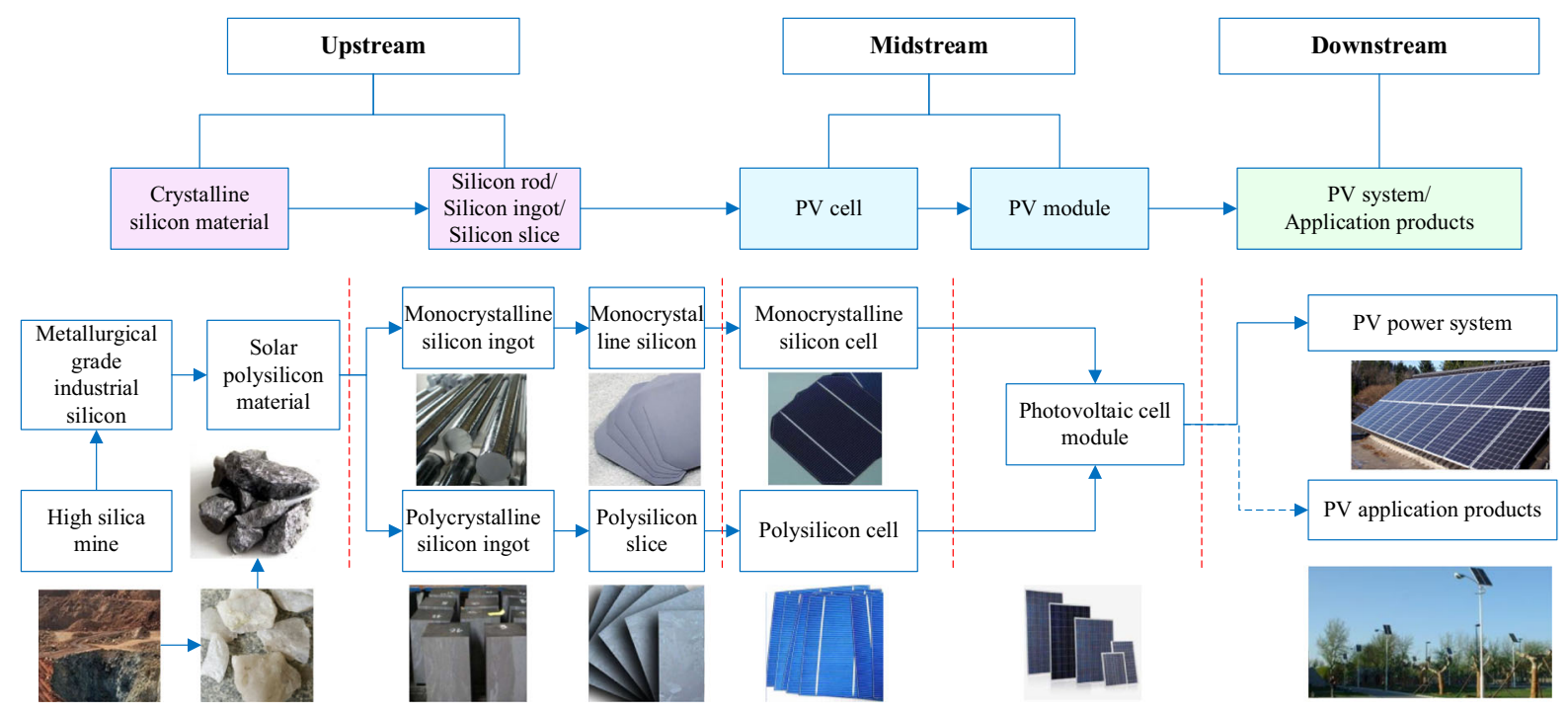

Fig. 1 The flow diagram of PV industry-chain 
which will trigger a variation of demand and installed capacity in a high probability. Based on above analysis, quantifying the influence of COVID-19 on China's PV gird parity should firstly clarify the influence path. Then it needs to consider PV production cost as a systems engineering and then design the corresponding sub-systems following the actual operations of PV power generation revenue.

The role of time cost in PV industry-chain

Based on the Product Life Cycle Theory, the time lag may bring the loss of market opportunity (Crosby 1979). With the variation of market environment, the competition mode changes from the primary level (e.g., price, variety and quality) to time competition level. Such time factor has become a high-quality resource in creating competitive edges because time cost is an important part of production cost.

It can be assumed that the output quality of PV power generated by $\mathrm{PV}$ system is $V$ where the constant cost is $X . X=\left\{x_{1}, x_{2}, \ldots, x_{n}\right\}$ indicates each of the production process cost. For the cost variable, the random disturbance cost is $Z$ where $Z=$ $\left\{z_{1}, z_{2}, \ldots, z_{n}\right\}$ indicates the disturbance cost of each operations process. Thus, $V$ can be expressed as a function of $X$ and $Z$ as Eq. (1).

$V=f(X, Z)=f\left(x_{1}, x_{2}, \ldots, x_{n} ; z_{1}, z_{2}, \ldots, z_{n}\right)$

In Eq. (1), the certification premise of products quality $V$ is that $V$ confirms to a certain quality standard $G$. When $G$ is the objective function, the rise of production process cost that satisfies $G$ will be influenced by both the fixed and random factors. In this context, assume that the output mass $V$ satisfies the normal distribution with the mean value as $\mu$ and variance as $\sigma^{2}$, the expected loss mass $V(E)$ can be expressed as Eq. (2).

$V(E)=E[k(V-G)]^{2}=k\left[\sigma^{2}+(\mu-G)^{2}\right]$

In Eq. (2), $k$ is the proportional constant in the quality loss. According to Eq. (2), the way for firms to ensure the product quality is to make the output quality of the system as close as the objective function $G$, which is equal to minimize the value of volatility $\sigma^{2}$. Accordingly, obtaining an $X$ expression that can minimize $\sigma^{2}$ seems quite important. Since $V$ is a function of $X$, the expectation of $V$ is also a function of
$X$. When the minimum output fluctuation is $\sigma^{2}$, the minimum value of $E(V)$ corresponding to $X=$ $\left\{x_{1}, x_{2}, \ldots, x_{n}\right\}$ can be obtained, i.e.,

$\min \sigma^{2}\left(x_{1}, x_{2}, \ldots, x_{n}\right)$

s.t. $\quad \mu\left(x_{1}, x_{2}, \ldots, x_{n}\right)=V$

In Eq. (3), the optimal investment proportion of process cost is $X^{*}=\left(x_{1}^{*}, x_{2}^{*}, \ldots, x_{n}^{*}\right)=E^{-1}\left(\mu^{*}, \sigma^{* 2}\right)$, where $\mu^{*}$ indicates the value of $\mu$ that is closest to $G$, and $\sigma^{* 2}$ satisfies the minimum of $\sigma^{2}$.

Further, the time cost is added to the production process of PV power. Assume that the increase cost of production process of $\mathrm{PV}$ power generation has the features of series topology. The average processing time of the $i$ th production process is $t_{i}$, with the fluctuation amplitude of time cost as $\sigma_{i}^{2}$, the conversion rate between production and value of each process as $J$, and the increase degree of product quality that brings by each additional unit cost as $J=X / V$. Then, according to the result of Hopp and Spearman (1996), the average waiting time between each two produce process can be expressed as Eq. (4).

$t_{i}=\left[\left(\sigma_{i-1}^{2}+\sigma_{i}^{2}\right) / 2\right][J /(J-1)] t_{i}$

The waiting time of the whole life cycle is as Eq. (5).

$T=\sum_{i=1}^{n}\left[\left(\sigma_{i-1}^{2}+\sigma_{i}^{2}\right) / 2\right][X /(X-V)] t_{i}$

According to the results of Eqs. (3) and (5), it can be concluded that: (1) the time cost $T$ of product life cycle increases with the improvement in quality $V$. (2) The time cost $T$ increases with the rise of the production process time $t_{i}$. (3) The time cost $T$ increases with the rise of the production process time. (4) When $X /(X-V)$ is small, i.e., the cost and quality being at a low level, the time cost mainly comes from the fluctuation brought about by $\sigma_{i-1}^{2}$. While when $X /(X-V)$ is large, i.e., the cost and quality being at a high level, the time cost mainly comes from the fluctuation brought about by $\sigma_{i}^{2}$.

According to Eq. (5), $T \propto\left(\sigma_{i-1}^{2}+\sigma_{i}^{2}\right) t_{i}$, which indicates that the cost time is proportional to working procedures' product time and the average waiting time, and thus the initial impact of COVID-19 on time is $\left(\sigma_{i-1+0}^{2}+\sigma_{i+0}^{2}\right) t_{i+0}$. Because the sudden shock of emergency fails to transmit its impact on the process 
cost at the initial time, it has no time lag effect of the initial impact of COVID-19 on the whole life cycle of PV power generation.

According to the analysis in this section, the functions of time, cost and quality in the production process can be transformed into each other, and thus the increased time process influenced by the pandemic will influence the cost and quality of final products. Under the condition of relatively low value conversion rate, the impact of production cycle extension on the upstream production process is more significant. Therefore, it is necessary to further characterize the cost impact of the whole value chain caused by the impact of the overall time-delay.

The cost system and sub-system of PV power generation cost

Based on the known relationship of system internal variables, system dynamics is an interdisciplinary and comprehensive subject, seeking for the better structure of the system to obtain the better system behavior. This method obtains the information feedback law between the system input and output with the assistance of simulation principle to finally understand and solve the systematic problems. This paper uses system dynamics to explore the shock scale of pandemic on China's PV power cost by simulating the specific influence route and forecasting the impact duration.

Currently, two indicators are selected to measure the income of PV power generation, including the internal rate of return (IRR) and the whole life cost of power consumption. Here, IRR is the discount of net cash flow of PV power projects in 25 years (the average life cycle of PV power system), and the whole life cost of power consumption is the ratio of total cost of PV power projects to the total power generation in 25 years. Based on the analysis of influencing factors to these two PV revenue indicators, it shows that the cost of PV power generation can be calculated by the following Equation as Eq. (6).

$T_{\text {cost }}=C_{\mathrm{p}}\left(1 /\right.$ Per $\left.+R_{\mathrm{op}}+R_{\text {loan }} * R_{\text {intr }}-I_{\text {sub }}\right) / H_{\text {fp }}$

where $T_{\text {cost }}$ indicates the cost price of PV power projects, with $C_{\mathrm{p}}$ indicating the unit installed cost of PV power projects, Per indicating the payback period of investment in device, and $R_{\mathrm{op}}$ indicating the long- term operations cost ratio of system. $R_{\text {loan }} * R_{\text {intr }}$ refers to the loan status in which $R_{\text {loan }}$ and $R_{\text {intr }}$ indicate the proportion of loans in investment and the lending rates, respectively. $I_{\text {sub }}$ is the ratio of fiscal subsidy, and $H_{\mathrm{fp}}$ is the average full-load equivalent. In this case, the revenue of PV power projects depends on four dimensions, i.e., the equivalent full-load hours, system cost, financing cost and subsidy income.

By analyzing the features of time-delay factor in the four cost dimensions of PV power generation, the equivalent full-load hours are the ratio between the power generation capacity and the installed capacity, which mainly relies on the natural conditions and actual demand of the location of PV landing projects, regardless of the completion and operations cycle of the PV power projects (Awasthi et al. 2020). In general, increasing the equivalent full-load hours by $1 \%$ can increase the IRR of PV power projects by $0.2-0.3 \%$. Therefore, this factor is not suitable to be directly selected as a sub-system related to time-delay factor. Something that needs to be explained is that the specific variables contained in this cost, e.g., power output, can be indirectly transmitted to the change of the whole life cost of power consumption through the variable selection of other sub-systems.

Second, the systematic cost of PV power projects consists of PV module, grid-connected inverter, PV support bracket and cost of total schedule for construction, among which the PV module cost accounts for $40.7 \%$ of initial investment cost of PV power project. Driven by the technology progress, price reduction in raw materials and other factors, China's PV modules have decreased by $90 \%$ in past 10 years, which is a major cost variable influenced by time-delay factor. It has been forecasted that the cost of this part would still have a larger decrease speed and space with the improvement in scale effect and transformation efficiency. However, as the largest exporter of PV industry, China's PV industry-chain is also influenced by the slowdown of overseas demand and the rise of freight price, and thus firms are forced to turn to domestic market competition.

As shown in Fig. 2, China's PV modules have strong dependence on the international market in the industry-chain of polycrystalline silicon slice, single crystalline silicon solar cell and polycrystalline silicon solar cell. Further, the price fluctuation in the international market has great 


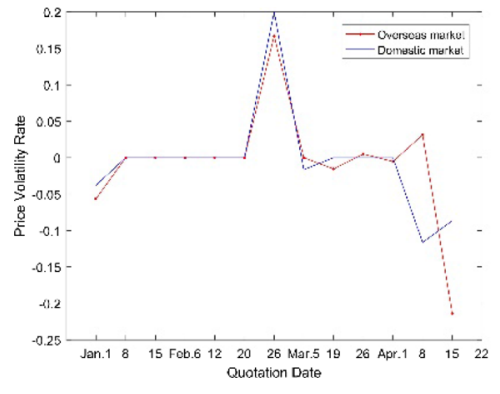

Pmonocrystalline silicon slice $($ Cor $=0.719)$

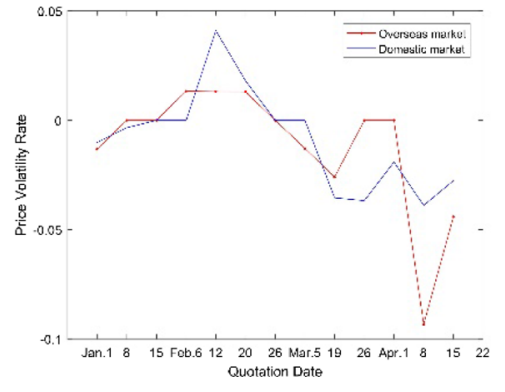

Polycrystalline silicon cell (Cor $=0.658)$

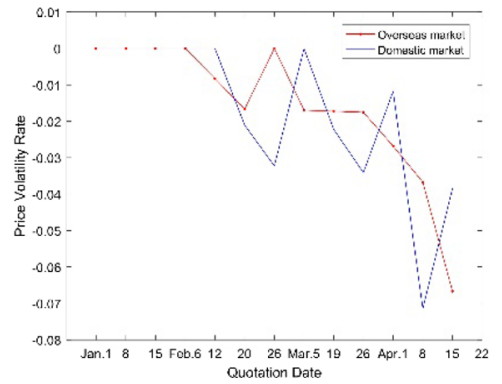

Monocrystalline silicon cell $($ Cor $=0.623)$

Fig. 2 The price volatility rate of PV modules between overseas market and China's domestic market

influence on the price fluctuation in the domestic market where the correlation influence coefficient is over 0.6. Due to the increasing competition in the domestic market and the pressure of de-stocking, the current round of price decrease in PV accessories is expected to last for at least $2-4$ weeks. Therefore, the systematic cost should be treated as one of the cost changing sub-system of PV power generation under the influence of time-delay factors.

Third, fiscal subsidy is an important driving force for the rapid development of China's PV industry (Fan et al. 2020). Based on the division of three types of subsidy coverage areas based on the local light intensity, the fiscal subsidy for China's PV industry provides 20 years' funds support for clean energy according to their actual PV power generation (Lin and Luan 2020). However, the default of fiscal subsidy, which easily triggers the shortage of cash flow in small- and medium-sized PV accessories firms, has become a main contradiction hindering the development of current China's PV industry, and this phenomenon will bring a capital crisis along the entire PV industry-chain with a high probability. According to the work plan for The 2019 Construction and Management of PV Power Generation issued by the National Energy Administration in May 2019, PV power projects included in the scope of fiscal subsidies should be completed and grid-connected with full capacity before the end of promised date in which the expected production time is declared. The document also states that if the grid connection is not completed within the time limit, the fiscal subsidy will be reduced by $0.01 \mathrm{yuan} / \mathrm{kWh}$ for each quarter overdue. While if the grid connection is not completed in 2 quarters after the promised date in which the production is declared, the qualification for fiscal subsidy would be canceled. Under this provision, more and more bidding projects in 2019 hope to realize grid connection before March 31 and June 30, 2020, thereby obtaining the corresponding fiscal subsidies. However, under the influence of the pandemic, there will be a large probability that the official release date of policies, e.g., electricity guiding price, will be delayed, and the roof negotiation of distributed power generation and the field survey of PV power landing projects will be influenced. In addition, it will not bring a great loss to China if it postpones the time-point of canceling the fiscal subsidy. Therefore, the postponement of fiscal subsidy has become a large probability event, which should be included in the influence sub-system of time-delay factor.

Fourth, with policy guidance, the current PV power projects is moving toward Distributed Power Generation. Since the new type of PV power projects has characters of small scales, large investment risks and low revenues, the investors are generally small- and medium-sized firms, where their main funds come from the financing of investment firms (Yang et al. 2019). Compared with bank lending, the financing cost of an investment firms is generally $9-12 \%$, and the financial cost during the operations period and the stabilization period of $\mathrm{PV}$ power projects is about $8-12 \%$ and $6-8 \%$ of the total investment. This part of cost is greatly influenced by the time-delay factor. In general, the return on capital decreases $0.8-1 \%$ when the financing cost increases by $1 \%$. Accordingly, the financing cost is an important sub-system that 
influences the cost of PV power generation by the shock of pandemics.

As shown in Fig. 3, in the framework of system dynamics, three sub-systems are selected to measure the impact of time-delay factor caused by pandemic on the cost of PV power generation.

\section{The forecast model for cost of PV power generation based on system dynamics}

According to the features of pandemics, this paper divides the cost influenced system of PV power generation into three sub-systems: investment cost, financing cost and fiscal subsidy income. Each subsystem influences and restricts each other according to the input and output changes of each influence index and jointly influences the cost of PV power generation.

Investment cost

From 2011 to 2018, although modules and inverters of PV industry decreased by more than $75 \%$, the investment cost of "module + inverter" is still accounted for more than $50 \%$ systematic cost of PV power generation. The key to further cost reduction in the Balance of System (BOS) of PV system lies in three aspects: the improvement in the module efficiency, the optimization of engineering design and the certain decrease space for the cost of PV modules.

In terms of investment cost, we need to focus on the impact of technological innovation and breakthrough on the cost of PV power generation. The cost of technology is a state variable, and the learning efficiency of technology as well as the average annual growth rate of PV installed capacity are two rate variables. The previous study shows that technology learning efficiency is influenced by a series of factors, e.g., photoelectric conversion rate of solar modules, which is essentially the conversion rate from input to output, and its dynamic features can be described by learning curve (Cui et al. 2019). The new installed capacity ratio of PV power projects is an important indicator to measure the development trend and industrial prospect of PV industry. With the strong support of national policies, China's new installed PV capacity ranks first in the world for six consecutive years. Although influenced by the Subsidy Reduction Policy (5.31 new deal of 2018) that the domestic new installed capacity decreased significantly in 2018 , the annual new installed PV projects in China are still as high as $68 \%$ during the period of 2010 to 2019 . This paper takes the learning efficiency and annual average growth rate of new installed PV projects as the main indicators in measuring investment cost, which can be expressed as Eq. (7) according to the method of Biondi and Moretto (2015).

$\mathrm{LCOE}_{t} \mathrm{PV}=\mathrm{LCOE}_{t_{0}}^{\mathrm{PV}} \exp \left(\alpha_{\mathrm{C}} t\right)$

In Eq. (7), $\alpha_{C}=\alpha \cdot \delta, \alpha=\ln (1-\theta) / \ln 2 ; \theta$ indicates the learning efficiency, and $\delta$ indicates the annual average growth rate. Based on the research results of Elshurafa et al. (2018), the value of learning efficiency $\theta$ of China's PV industry is 0.084 .

Second, since the cost of PV modules accounts for about half of the total cost of PV power projects and there is a high correlation between the domestic market and international markets regarding as the module price volatility, the weak in module prices has driven down the initial investment. Different from the drop of module price caused by the unique demand shock of the traditional raw material market, the

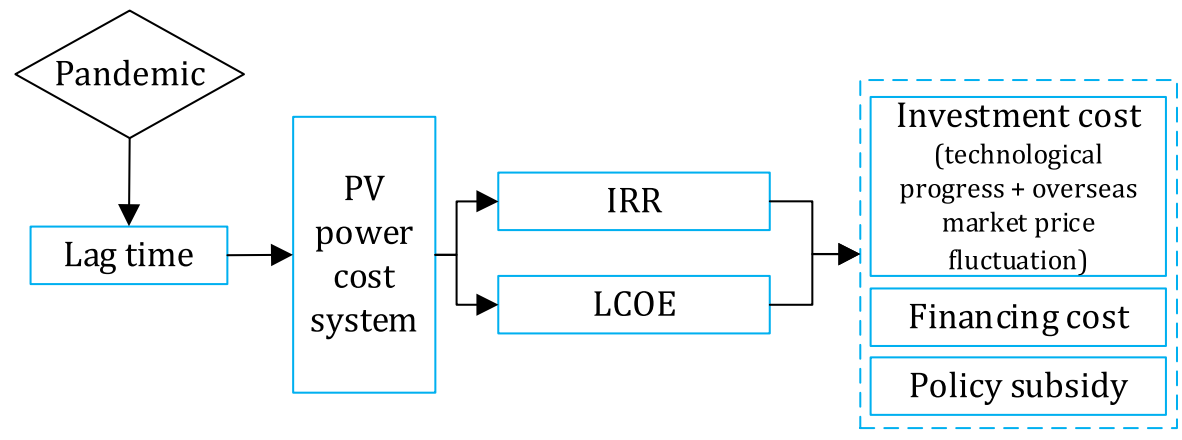

Fig. 3 The cost sub-system of PV power generation under the pandemics shock 
module price fluctuation caused by the pandemic is more reflected in the impact wave of exchange rate, production cost and total demand. It is the fluctuation of both sides of supply and demand under the interference of the pandemic that influences the price of PV modules (Yu et al. 2012). The impact of the pandemic on the demand side mainly triggers the fact that the spread of the pandemic has delayed or slowed the progress of the PV power project. From February to March of 2020, the pandemic has seriously shocked the production of China's PV accessories, resulting in an increase in the price of PV modules. Then, after the work returning of China's PV firms, the overcapacity and inventory rise further shock the supply side of China's PV industry because the spread of the overseas pandemic brings the postponement of overseas PV power projects that decrease the actual demand of PV accessories. From March to April, the weak of international PV market began to influence the whole PV industry-chain, where the price of PV accessories showed an obvious downward trend. In view of the fact that the price fluctuation of PV modules in the international markets has a conduction strength of about $60 \%$ to the price of domestic PV modules, we forecast the price fluctuation of PV modules based on the time-delay lag factor of pandemic influence.

\section{Financing cost}

According to the industry standard of PV power generation, the yield of PV power is determined by the lighting conditions of the installation area, where the annual technical attenuation is $0.5 \%$ within the 25-year usage cycle of PV modules. In general, the $\mathrm{PV}$ power projects has the features of low maintenance cost, stable income and the excellent property of financing. However, since the financing period for PV power generation is relative long, the investors obligate high market risk, which brings more policy and technical uncertainty for this industry (JimenezCastillo et al. 2020). Therefore, this paper focuses on the time cost and scale benefit of financing when considering the sub-system construction of financing cost.

The sub-system of financing cost consists of two parts: financing rate and financing scale. Financing rate is the borrowing time cost during the process of capital concession and usage, which can be expressed as Eq. (8).

$\mathrm{Kr}=\frac{(i+\mathrm{Vr})\left(1-t_{a}\right)}{1-f}$

where $\mathrm{Kr}$ is the financing rate, $i$ is the loan interest rate, $t_{a}$ is the income tax rate, $f$ is the money raising rate. Here, $\mathrm{Vr}$ is the guarantee rate, in which calculation formula can be constructed as Eq. (9).

$V r=\frac{\mathrm{V}}{\mathrm{P} \times n} \times 100 \%$

where $V$ refers to the total amount of guarantee, $P$ refers to the total amount of financing, and $n$ refers to the period of fundraising.

Financing scale mainly consists of investment cost and operations cost. For the investment process, the cost of financing is hedged by the income of the PV power sale. During the investment process, the cost of financing can be hedged by the income of the PV power sale. Because the PV operations revenue is affected and influenced by several factors, e.g., power generation and the abandoned electricity rate of PV power generation, the sub-index of equivalent fullload hours also influences the financing scales by influencing the power generation and installed capacity.

Fiscal subsidy income

Fiscal subsidy is an important factor to promote the PV industry, accounting for nearly $1 / 5$ of the actual revenue of PV power projects. In the context of the continuous decrease in fiscal subsidies, the income effect of this sub-system to the PV power generation cost continues to decrease. However, due to the pandemics, the delay of historical subsidy and the release delay of new subsidy policy, this sub-system will still provide the benefits for the PV power generation in the short term. This paper describes the input-output process of the sub-system of fiscal subsidy by using the subsidy rate formed by different subsidy intensity and the time-delay factor caused by the subsidy delay.

On the construction of three sub-systems, the impact of time-delay factor on the whole industrychain of China's PV power projects is considered, which mainly focuses on three paths as follows. 
(1) Time lag $\rightarrow$ Unit cost change (Installation growth) $\rightarrow$ Investment cost $\rightarrow$ Cost change $\rightarrow$ LCOE

(2) Time lag $\rightarrow$ Subsidy change $\rightarrow$ Subsidy income $\rightarrow$ Cost change $\rightarrow$ LCOE

(3) Time lag $\rightarrow$ Financing period $\rightarrow$ Guarantee fee change $\rightarrow$ Financing change $\rightarrow$ Financing cost $\rightarrow$ Cost change $\rightarrow$ LCOE

In the specific model construction of system dynamics, the main state equation and rate equation in measuring the cost PV power projects are as follows:

State equation:

$$
\begin{aligned}
& \text { (1) } \quad \text { COE }=(1+\text { Cost change }) * \text { Fixed } \\
& \text { cost }+ \text { Operations cost }
\end{aligned}
$$

where Fixed Cost includes Investment Cost, Financing Cost and Subsidy Income.

Rate equations:

(1) Unit cost change $=($ Technology learning rate + Module price volatility) * Time lag

(2) Installed growth = Growth factor * Time lag

(3) Capital demand = Investment Cost + Operations cost

(4) Financing demand change $=($ Guarantee rate + Loan interest rate $) /(1-$ Income tax rate) * Time lag

(5) Subsidy change $=$ Subsidy Intensity * Time lag

Then all equations are put into the system dynamics model to get the display expression of relevant variables and forecast the future cost trend of PV power generation under different time-delay factors, as shown in Fig. 4.

\section{Results and analysis}

Data collection and robustness test

Before simulating the results of pandemic shock on PV power generation, known constants and table functions should be firstly provided to be the input of the systematic dynamics model. Specifically, known constants include the subsidy intensity of LCOE, the growth rate of new installed capacity, installed capacity, power generation and other results that can be directly obtained by searching relevant statistical data. Table functions include unit cost change rate, financing rate, capital demand, etc., which are used to deal with the complex linear relationship among variables by deducing corresponding historical data and giving the approximate trend range. Based on the average financing level of non-bank financial institutions, The Annual Report of China's PV Industry, and Several Opinions on Promoting the Healthy Development of Non-Water Renewable Energy Power Generation, the values of each parameter in the model are obtained, as shown in Table 1.

Based on the built model in "The forecast model for cost of PV power generation based on system" section, the influence intensity of cost change of each sub-system on total LCOE of PV power generation can be forecasted.

The results of robustness test in Fig. 5 show that changing time intervals do not significantly influence the price trend of main sub-systems. This result also supports that the system dynamics model constructed in this paper is reasonable and can be used to forecast the impact of COVID-19 on PV industry.

Results analysis

As the fiscal subsidy for PV industry will probably end in 2021, this paper only gives the results of the impact of the pandemic on the investment and financing subsystem of PV power projects under different timedelay factors.

It can be seen from Fig. 6 that, first of all, with the rise of the production quarter influenced by the pandemic, the investment cost of LCOE shows a trend of small rise first and then steady and rapid decrease, where the decline degree increases with the rise of the influence quarters. The improvement in PV system efficiency, tracking technology and the application of double-sided module raises the investment cost of PV power generation. Compared with the PV power projects built in the earlier stage, the newlyinstalled PV power projects in the later stage can increase the power generation capacity and reduce the power consumption cost within the period of time lag. At the same time, as shown in "The framework of PV industry's cost system and sub-system design" section, the promotion of PV quality and cost depends 


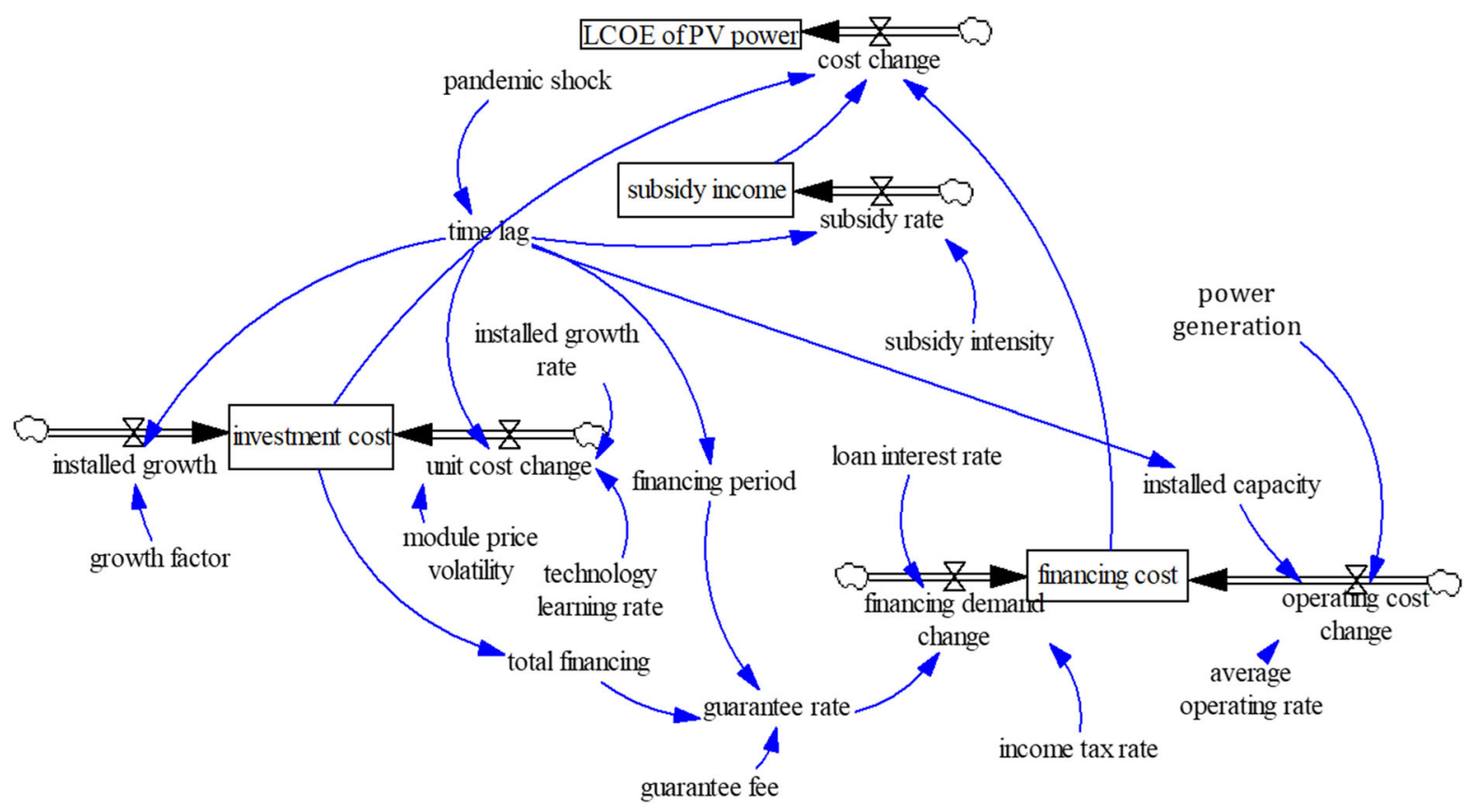

Fig. 4 The model structure of LCOE of PV power generation under time lag

Table 1 The parameter values of PV power generation cost

\begin{tabular}{ll}
\hline Parameters & Values \\
\hline Total financing (Billion Yuan) & 210.7 (2019),1.2 (Quarter I of 2020) \\
Income tax rate (\%) & 12.5 \\
Loan interest rate (\%) & 6 (Average value) \\
Average operating rate (\%) & 2 (Average value) \\
Module price volatility (\%) & -5 (Average value) \\
Installed growth rate (\%) & 12 (Based on data of 2013-2018) \\
Subsidy intensity (Yuan) & 0.1 (10\% quarterly reduction from Q2) \\
Power generation (GW) & 177,500 (2019 data) \\
Installed capacity (GW) & 130.58 (2019 data) \\
\hline
\end{tabular}

more on the level improvement in upstream manufacturing. By optimizing the design of PV power generation and adopting efficient modules, the investment cost of PV power projects can be further reduced. Second, the financing cost shows a steady upward trend because the pandemic that influences the production cycle, and the increase degree of the later period is larger than that of the earlier period. Here, we can conclude that influenced by the pandemic, the key factor that restricts the further reduction the cost of PV power generation is financing cost. As the example of this paper, the rise of financing cost exceeds the rise of investment cost in the short-term time lag, which becomes the largest part of cost composition. Third, the increase and decrease in investment and financing costs are overlapped. For the short-term time lag, the cost of PV power projects has upward pressure. While for the long-term time lag, the cost of PV power projects has a significant downward trend because the decrease in investment cost is faster than the rise of financing cost. For the short term, the time lag makes the insufficient supply of PV modules, which leads to the rise of supply chain cost. While the capital demand caused by shutdown and default pushes up the financing cost, which makes the superposition of these two factors offset the price decrease brought by 


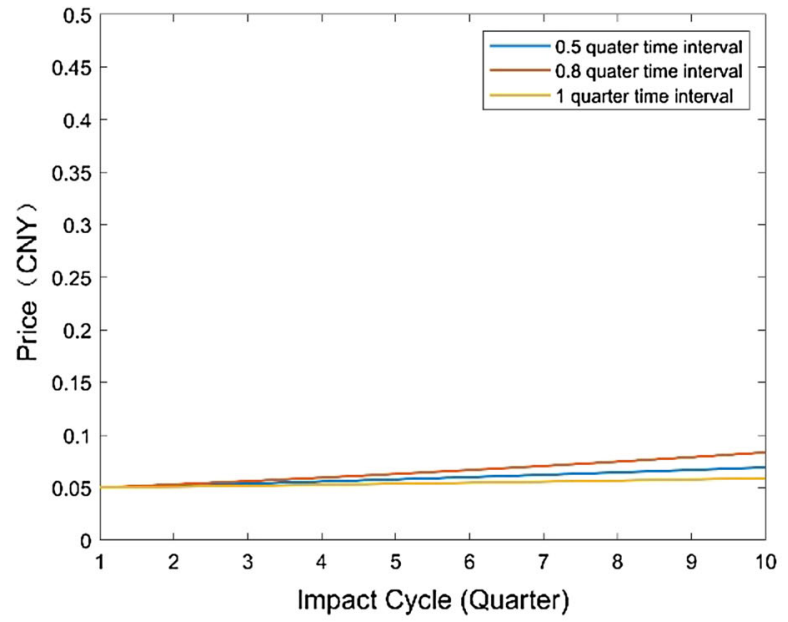

(a) Financing cost

Fig. 5 Robustness test

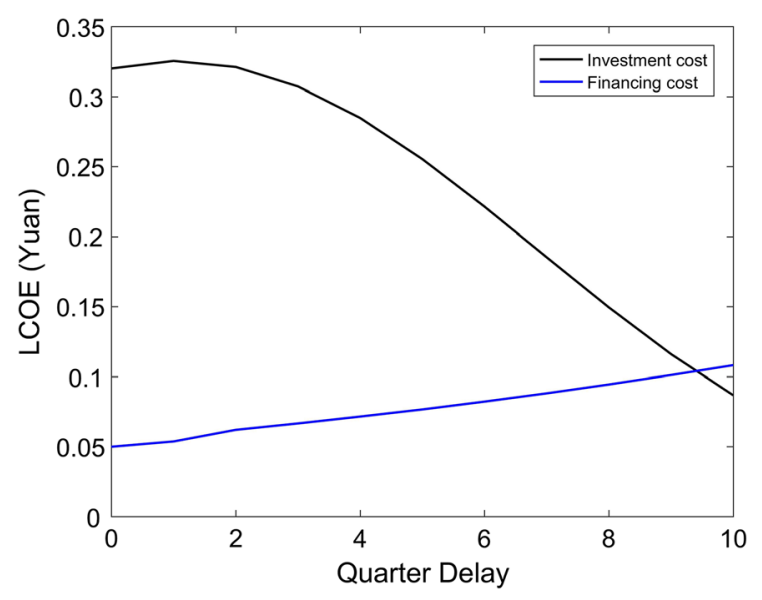

Fig. 6 The investment and financing cost of PV power generation under COVID-19 shock

technological progress, further aggravating the rise of investment cost of short-term PV power projects. For the long term, the double decrease in installed growth rate and capital demand is brought by the large-scale production stop, which helps reduce the investment cost that essentially impedes the long-term development of PV industry due to the production stagnation in the whole industry-chain.

As we have analyzed previously, the impact of the pandemic on PV power generation is a short-term impact. Therefore, this paper uses the time lag of one and two quarter to simulate the mid-term cost trend of PV power projects under the condition of pandemic shock.

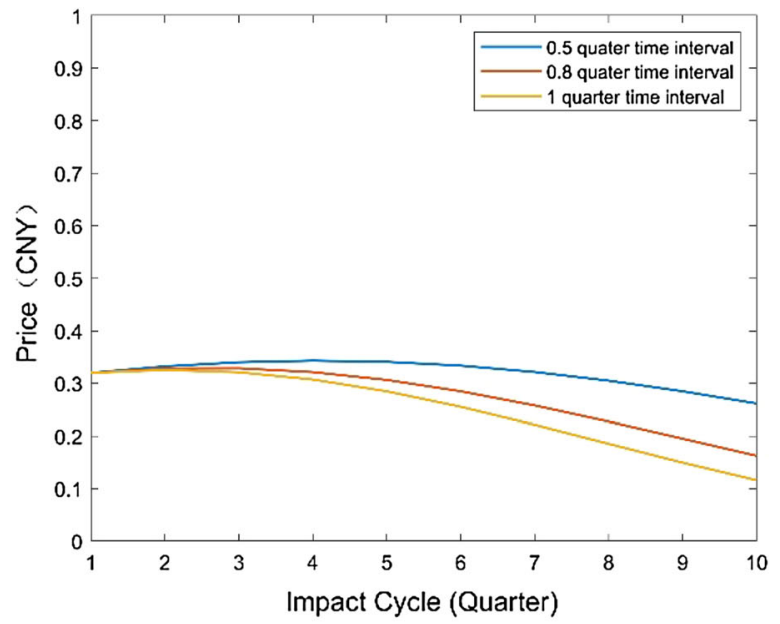

(b) Investment cost

As shown in Table 2, the impact of unit financing cost on total cost of PV power projects has increased rapidly, and the volatility of financing cost has increased by more than $7.5 \%$ for the one quarter time lag and $15 \%$ for the two quarters time lag compared with that before the pandemic. In contrast, due to the cost decrease brought by technological progress and the weakness of price module in the international market, the rise of unit investment cost caused by production stagnation in the proportion of total cost is relatively small, with an increase of about $1.7 \%$ for the one quarter time lag and $0.34 \%$ for the two quarters time lag. However, due to the deferral of fiscal subsidy, unit subsidies have a better effect on reducing the cost of PV power generation. In general, the cost of $\mathrm{PV}$ power generation caused by the pandemic lagged behind one quarter rose by about $2.53 \%$, and two quarters by about $2.45 \%$. In view of the production resumption of China's PV manufactures in April 2020, we simulate the expected trend of the overall LCOE with one quarter time lag. Based on the transmission regulation in cost along the industry-chain proposed by Hernandez-Moro and Martinez-Duart (2013), we can forecast the future LCOE of PV power projects as Fig. 7.

The black line in Fig. 7 shows the forecast LCOE trend of new installed PV power project. By the shock of the pandemic, the simulation result of the blue dotted line shows that one quarter time lag will promote the LCOE of PV power to rise significantly in 
Table 2 The volatility range of PV power generation cost under the impact of COVID-19

\begin{tabular}{lclll}
\hline Unit volatility & Financing cost $(+)(\%)$ & Investment cost $(+)(\%)$ & Subsidy income $(-)(\%)$ & Total LCOE $(+)(\%)$ \\
\hline Quarters delay & & & & \\
1 & 7.58 & 1.69 & 0 & 2.53 \\
2 & 15.66 & 0.34 & 14.28 & 2.45 \\
\hline
\end{tabular}

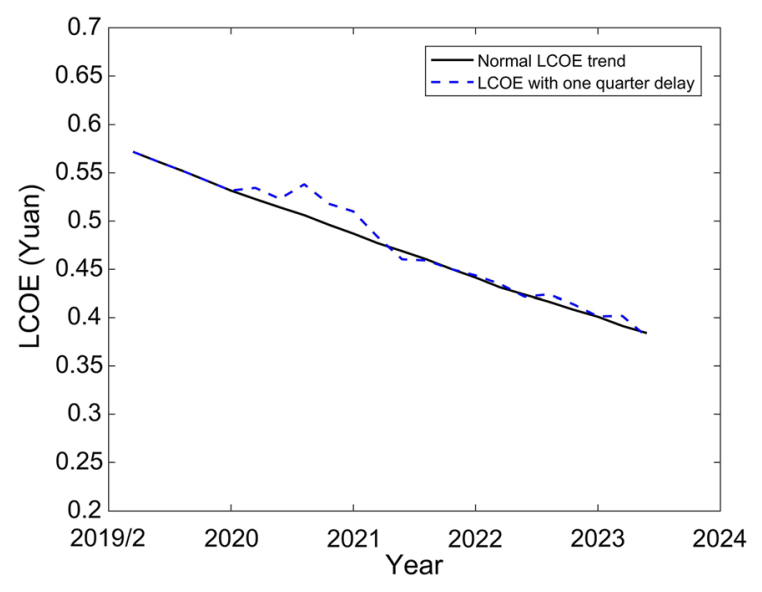

Fig. 7 The LCOE trend of PV power generation under the influence of COVID-19

the second quarter of 2020, and this rise will appear a callback in the fourth quarter of 2020 with the resumption of work and the rise of new PV installation demand, where the impact of this emergency on the PV power industry will end in the first quarter of 2021.

To sum up, although the pandemic makes the PV module manufacturing face shutdown and the construction period of the power projects is extended, the total impact of COVID-19 on the LCOE of PV power generation is controllable, and the industry still shows a good development trend as a whole. The reason for this conclusion lies in that with the high level of automation, the lower proportion cost of labor payment and the strong downstream demand, and thus the losses caused by the resumption lag can be alleviated by high automation after the resumption of PV manufacture firms. The results further point out that in the short term, the increased LCOE of PV power generation is not conducive to the completion of the mission of new installed power generation in 2020 . Currently, influenced by the pandemic, the overall PV industry is facing the following three problems. First, the extension of financing cycle leads to the rise of capital cost. Second, the logistics factor leads to the rise of delivery risk. Third, the deterioration of foreign trade environment and international policies lead to the expected demand fluctuation. Accordingly, in view of the impact of the pandemic on the PV industry, the government needs to adjust the industrial support policies. While firms need to grasp the development direction of PV industry, and thus timely adjust the production and power projects construction strategies and effectively responding to the pandemic challenges based on above three areas.

\section{Conclusions and research implications}

\section{Conclusions}

Based on the law of cost conduction and system dynamics model, this paper analyzes the pandemic impact on China's PV power projects at the respect of influence intensity and action period, where the conclusions are as follows. (1) The impact of the pandemic on the PV industry has a time-delay effect, and the shock period of this virus on China's stoppage is about one quarter. (2) The impact of the pandemic on the upstream firms of the PV industry-chain is greater than that on the downstream firms, and the final performance of the impact results is the LCOE fluctuation of the new installed PV power projects. (3) The price drop of PV modules caused by the spread of overseas viruses has little impact on the cost of domestic PV power projects of China. The trend of financing and investment cost caused by the pandemic shows that the cost of new installed PV power projects is under increasing pressure in the short term, in which the increase rate is about $3 \%$. (4) The rising cost of PV power generation caused by pandemics will decrease rapidly with the overall resumption of production in the whole industry-chain and will basically return to 
the original expected trend of parity on grid by the end of 2020 .

\section{Management implications}

Due to the sudden, complex and sustained shock of COVID-19, in order to reduce the impact of the pandemic on China's PV parity on grid in 2020, the following policy and management implications are proposed based on the conclusions of the study.

First, it should further support the upstream firms of PV module manufactures to get out of the financing cost dilemma, and thus prevent the excessive transfer of financing cost to the cost of PV power generation along with the industry-chain. Our findings show that financing cost is an important problem restricting the development of PV industry in China. Thus, we need to innovate diversified financing methods to support financial institutions to reduce firms' financing cost. The content of this policy includes two parts. One is that the financial institutions are encouraged to provide credit loan support to small and mediumsized firms at the upstream of PV industry-chain, which helps appropriately reduce the rate of guarantee and re-guarantee and also reduce taxes as well as extending the use cycle of funds. The other is that recognize the cost stable role of small and mediumsized suppliers in the PV industry-chain, and thus further protecting their business environment. The government should not formulate fiscal support policies related to PV industry based on an absolute scale, which aggravates the "crowding out effect" to small and medium-sized suppliers since the most fiscal support is to large suppliers.

Second, the upgrade of PV industry based on digital and intelligent transformation. The essence of the impact of the COVID-19 on PV industry lies in the increase in the time lag cost caused by the limited travel of workers and the stagnation of transportation. With the help of digital tools, it should improve the management efficiency of PV manufactures' capacity in logistics, and thus timely achieve the tracking of product status, transparent supervision and deployment control. By the digital transformation, it can enhance the vitality of data assets in PV industry and bridge the upstream and downstream value of supply chain in the form of data docking, which broads the marketing channels among suppliers of PV industry and improves the anti-risk capability of whole industry-chain. At the same time, increasing the attempt of unmanned logistics technology can also reduce the risk of supply chain rupture of PV industry brought by logistics disruption.

Third, strengthen cost control to timely adjust the output. In a stagnant market environment, high startup rate is equivalent to high inventory. Under the current high uncertain market, the inventory value loss caused by the excessive fluctuation of raw material price is far greater than the income brought by the high start-up rate. At the same time, the occupation of cash flow caused by high start-up rate is easy to push up the financing risk of PV power generation firms; and in extreme cases, there will be a situation of selling inventory to obtain cash flow regardless of the cost. Thus, during the period of weak market demand, firms should suspend the production of PV power projects and carry out the investment and development of projects unless the price of raw material of PV industry is judged at historically low levels, and the volatility of module cost can be accepted.

Acknowledgements Funding was provided by The Ministry of Education of Humanities and Social Science Project (20YJ C630123). Natural Society Science Foundation of China (Grant No. 19BGL100). National Natural Science Foundation of China (Grant No. 71803074).

\section{References}

Al Hadi, A., Silva, C. A. S., Hossain, E., \& Challoo, R. (2020). Algorithm for demand response to maximize the penetration of renewable energy. IEEE Access, 8, 55279-55288.

Awasthi, A., Shukla, A. K., Manohar, S. R. M., Dondariya, C., Shukla, K. N., Porwal, D., et al. (2020). Review on sun tracking technology in solar PV system. Energy Reports, 6 , 392-405.

Binz, C., Tang, T., \& Huenteler, J. (2017). Spatial lifecycles of cleantech industries: The global development history of solar photovoltaics. Energy Policy, 101, 386-402.

Biondi, T., \& Moretto, M. (2015). Solar grid parity dynamics in Italy: A real option approach. Energy, 80, 293-302.

Cai, H., Liang, L., Tang, J., Wang, Z., Wei, L., \& Xie, H. (2019). An empirical study on the efficiency and influencing factors of the Photovoltaic industry in China and an analysis of its influencing factors. Sustainability, 11, 23.

Chen, J., Liu, G., Kang, Y., Wu, B., Sun, R., Zhou, C., et al. (2014). Coal utilization in China: Environmental impacts and human health. Environmental Geochemistry and Health, 36, 735-753.

Chen, Z., \& Su, S. I. (2018). Multiple competing photovoltaic supply chains: Modeling, analyses and policies. Journal of Cleaner Production, 174, 1274-1287. 
Corwin, S., \& Johnson, T. L. (2019). The role of local governments in the development of China's solar photovoltaic industry. Energy Policy, 130, 283-293.

Crosby, P. B. (1979). Quality is free: The art of making quality certain. New York: Mc Graw-Hill.

Cui, Y., Ji, D., Liu, W., \& Cheng, Y. L. (2019). Research on the cost of distributed photovoltaic plant of China based on whole life cycle perspective. IEEE Access, 7, 89379-89389.

Ding, M., Xu, Z., Wang, W., Wang, X., Song, Y., \& Chen, D. (2016). A review on China's large-scale PV integration: Progress, challenges and recommendations. Renewable and Sustainable Energy Reviews, 53, 639-652.

Ding, H., Zhou, D., Liu, G., \& Zhou, P. (2020). Cost reduction or electricity penetration: Government R\&D-induced PV development and future policy schemes. Renewable and Sustainable Energy Reviews, 124, 109752.

Elshurafa, A. M., Albardi, S. R., Bigerna, S., \& Bollino, C. (2018). Estimating the learning curve of solar PV balanceof-system for over 20 countries: Implications and policy recommendations. Journal of Cleaner Production, 196, 122-134.

Fan, J., Zeng, B., Hu, J., Zhang, X., \& Wang, H. (2020). The impact of climate change on residential energy consumption in urban and rural divided southern and northern China. Environmental Geochemistry and Health, 42, 969-985.

Fang, H., Wang, B., \& Song, W. (2020). Analyzing the interrelationships among barriers to green procurement in photovoltaic industry: An integrated method. Journal of Cleaner Production, 249, 119408.

Hernandez-Moro, J., \& Martinez-Duart, J. M. (2013). Analytical model for solar PV and CSP electricity costs: Present LCOE values and their future evolution. Renewable and Sustainable Energy Reviews, 20, 119-132.

Hopp, W., \& Spearman, M. (1996). Factory physics: Foundation of manufacturing management. New York: Irwin.

Ibarloza, A., Heras-Saizarbitoria, I., Allur, E., \& Larrea, A. (2018). Regulatory cuts and economic and financial performance of Spanish solar power companies: An empirical review. Renewable and Sustainable Energy Reviews, 92, 784-793.

Javaid, M., Haleem, A., Vaishya, R., Bahl, S., Suman, R., \& Vaish, A. (2020). Industry 4.0 technologies and their applications in fighting COVID-19 pandemic. Diabetes \& Metabolic Syndrome: Clinical Research \& Reviews, 14(4), 419-422.

Jimenez-Castillo, G., Munoz-Rodriguez, F. J., Rus-Casas, C., \& Talavera, D. L. (2020). A new approach based on economic profitability to sizing the photovoltaic generator in selfconsumption systems without storage. Renewable Energy, 148, 1017-1033.

Lane, D. C. (1999). Social theory and system dynamics practice. European Journal of Operational Research, 113(3), 501-527.

Li, Z. (2003). SARS will influence the short-run and long-run analysis on the national economy. Economics Science, 25(3), 25-31. (in Chinese).

Li, M., Zhou, W., Lu, H., \& Fang, J. (2010). Robust control for a generic linear rational expectations model of economy.
Applied Mathematics and Computation, 216(7), 2145-2154.

Lin, B., \& Luan, R. (2020). Do government subsidies promote efficiency in technological innovation of China's photovoltaic enterprises? Journal of Cleaner Production, 254, 120108

Liu, J., \& Liu, X. (2019). Empirical analysis and strategy suggestions on the value-added capacity of photovoltaic industry value chain in China. Energy, 180, 356-366.

Liu, Y., Shuai, C., \& Ding, L. (2016). Financial risks of solar photovoltaic companies: Do managerial power and ownership concentration really matter? Empirical evidence from China. Journal of Renewable and Sustainable Energy, 8(4), 045901.

Mamat, A., Zhang, Z., Mamat, Z., Zhang, F., \& Chen, Y. (2020). Pollution assessment and health risk evaluation of eight (metalloid) heavy metals in farmland soil of 146 cities in China. Environmental Geochemistry and Health, in press.

McBee, K. D., Chong, J., \& Rudraraju, P. (2019). Demand side management effects on substation transformer capacity limits. Applied Science, 9(16), 3266.

Mehrjerdi, H. (2019). Multilevel home energy management integrated with renewable energies and storage technologies considering contingency operation. Journal of Renewable \& Sustainable Energy, 11(2), 025101.

Mirzania, P., Ford, A., Andrews, D., \& Ofori, G. (2019). The impact of policy changes: The opportunities of community renewable energy projects in the UK and the barriers they face. Energy Policy, 129, 1282-1296.

Moslehi, S., \& Reddy, T. A. (2019). A new quantitative life cycle sustainability assessment framework: Application to integrated energy systems. Applied Energy, 239, 482-493.

Ntemi, M., \& Kotropoulos, C. (2020). A dynamic dyadic particle filter for price prediction. Signal Processing, 167, 107334.

Ren, M., Mitchell, C. R., \& Mo, W. (2020). Dynamic life cycle economic and environmental assessment of residential solar photovoltaic systems. Science of the Total Environment, 722, 137932.

Schmitz, M., Garcia, V. J., \& Bernardon, D. P. (2019). Matheuristic for emergency response in the electric distribution system with unforeseen islanding. Electric Power Systems Research, 169, 1-17.

Shang, J. S. (2017). Study on industry price transmission based on input-output model with time delay. Statistics \& Information Forum, 32(5), 43-50. (in Chinese).

Starnini, M., Boguna, M., \& Serrano, M. A. (2019). The interconnected wealth of nations: Shock propagation on global trade-investment multiplex networks. Scientific Reports, 9, 13079.

Sun, C., Li, N., \& Xu, Z. (2019). System dynamics simulation on transaction cost influencing factors of EPC between general contractor and sub-contractors. Soft Science, 33(9), 92-98. (in Chinese).

Sun, H., Zhi, Q., Wang, Y., Yao, Q., \& Sun, J. (2014). China's solar photovoltaic industry development: The status quo, problems and approaches. Applied Energy, 118, 221-230.

Tong, R. C. (2010). The price transmission model considering production delays. The Journal of Quantitative \& Technical Economics, 8, 139-152. (in Chinese). 
Vaka, M., Walvekar, R., Rasheed, A. K., \& Khalid, M. (2020). A review on Malaysia's solar energy pathway towards carbon-neutral Malaysia beyond Covid'19 pandemic. Journal of Cleaner Production, 273, 122834.

Wang, Q., Qu, J., Wang, B., Wang, P., \& Yang, T. (2019). Green technology innovation development in China in 1990-2015. Science of the Total Environment, 696, 134008.

Wang, L., \& Wang, Y. (2018). Research on the condition mechanism of photovoltaic industry chain risk evolution based on dissipative structure theory. Soft Science, 32(1), 25-30. (in Chinese).

Yang, C., Yao, R., \& Zhou, K. (2019). Forecasting of electricity price subsidy based on installed cost of distributed photovoltaic in China. Energy Procedia, 158, 3393-3398.

Yao, M., \& Cai, X. (2019). An overview of the photovoltaic industry is status and perspective in China. IEEE Access, 7, 181051-181060.

Ye, B., Jiang, J., Zhou, Y., Liu, J., \& Wang, K. (2019). Technical and economic analysis of amine-based carbon capture and sequestration at coal-fired power plants. Journal of Cleaner Production, 222, 476-487.

Ye, B., Yang, P., Jiang, J., \& Miao, L. (2017). Feasibility and economic analysis of a renewable energy powered special town in China. Resources, Conservation and Recycling, 121, 40-50.

Yu, Y., Song, Y., \& Bao, H. (2012). Why did the price of solar PV Si feedstock fluctuate so wildly in 2004-2009? Energy Policy, 49, 572-585.

Zhu, L., Xu, Y., \& Pan, Y. (2019). Enabled comparative advantage strategy in China's solar PV development. Energy Policy, 133, 110880.

Zhu, X., Zhang, H., Huang, J., Shao, L., \& Guo, Y. (2018). The impact of emergencies on national metal resource security. Resources Science, 40(3), 486-497. (in Chinese).

Publisher's Note Springer Nature remains neutral with regard to jurisdictional claims in published maps and institutional affiliations. 